\title{
Anatomia foliar como subsídio à taxonomia de Hippocrateoideae (Celastraceae) no Sudeste do Brasil ${ }^{1}$
}

\author{
Sandra Maria Alvarenga Gomes ${ }^{2,5}$, Eldo Antônio Monteiro da Silva ${ }^{3}$, Julio Antonio Lombardi ${ }^{4}$, \\ Aristéa Alves Azevedo ${ }^{3}$ e Fernando Henrique Aguiar Vale ${ }^{4}$
}

Recebido em 26/01/2005. Aceito em 07/06/2005

\begin{abstract}
RESUMO - (Anatomia foliar como subsídio à taxonomia de Hippocrateoideae (Celastraceae) no Sudeste do Brasil). A anatomia foliar de treze espécies pertencentes a nove gêneros da subfamília Hippocrateoideae (Celastraceae) foi estudada visando a seleção de caracteres anatômicos para subsidiar a taxonomia dos gêneros e espécies. As espécies estudadas foram: Anthodon decussatum Ruiz \& Pav., Cheiloclinium cognatum (Miers) A.C. Sm., Cheiloclinium serratum (Cambess.) A.C. Sm., Cuervea crenulata Mennega, Elachyptera micrantha (Cambess.) A.C. Sm., Hippocratea volubilis L., Peritassa flaviflora A.C. Sm., Peritassa mexiae A.C.Sm., Pristimera nervosa (Miers) A.C. Sm., Salacia crassifolia (Mart. ex Schult.) G. Don, Tontelea fluminensis (Peyr.) A.C. Sm., Tontelea leptophylla A.C. Sm. e Tontelea miersii (Peyr.) A.C. Sm. Os caracteres anatômicos selecionados como diagnósticos para a taxonomia dos diferentes gêneros e espécies são: o tipo de esclereíde presente no pecíolo ou na lâmina foliar, o tipo de estômato, a conformação do sistema vascular do pecíolo, a sinuosidade das paredes anticlinais das células epidérmicas, a presença de hipoderme, a ocorrência de laticíferos, dentre outros.
\end{abstract}

Palavras-chave: Hippocrateoideae, Celastraceae, anatomia foliar, taxonomia

\begin{abstract}
Leaf anatomy as taxonomic tool for Hippocrateoideae (Celastraceae) in the Southeast of Brazil). Leaf anatomy of thirteen species belonging to nine genera of the subfamily Hippocrateoideae (Celastraceae) was studied, in order to select anatomical characters to help the taxonomy at genera and species levels. The species studied were: Anthodon decussatum Ruiz \& Pav., Cheiloclinium cognatum (Miers) A.C. Sm., Cheiloclinium serratum (Cambess.) A.C. Sm., Cuervea crenulata Mennega, Elachyptera micrantha (Cambess.) A.C. Sm., Hippocratea volubilis L., Peritassa flaviflora A.C. Sm., Peritassa mexiae A.C. Sm., Pristimera nervosa (Miers) A.C. Sm., Salacia crassifolia (Mart. ex Schult.) G. Don, Tontelea fluminensis (Peyr.) A.C. Sm., Tontelea leptophylla A.C. Sm. and Tontelea miersii (Peyr.) A.C. Sm. The selected anatomical characters that can be used as diagnostic for the taxonomy of the distinct genera and species are: the type of sclereids in petiole or leaf blade, stomata type, the conformation of the petiole vascular system, shape of epidermal cell walls, presence of hypodermis, occurrence of laticifers, among others.
\end{abstract}

Key words: Hippocrateoideae, Celastraceae, leaf anatomy, taxonomy

\section{Introdução}

A família Hippocrateaceae hoje é incluída em Celastraceae como uma subfamília com cinco tribos, 24 gêneros e cerca de 357 espécies descritas (Hallé 1990; Mennega 1997) distribuídas nas áreas tropicais e subtropicais do mundo. No Brasil, ocorrem 12 gêneros (Smith 1940) e cerca de 70 espécies (Barroso et al. 1984). Na região sudeste do Brasil ocorrem 10 gêneros e 33 espécies: Anthodon Ruiz \& Pav. (uma sp.), Cheiloclinium Miers (três sp.), Cuervea Miers (uma sp.), Elachyptera A.C. Sm. (duas sp.), Hippocratea L. (uma sp.), Peritassa Miers (sete sp.), Pristimera
Miers (duas sp.), Salacia L. (seis sp.), Semialarium N. Hallé (uma sp.) e Tontelea Aubl. (nove sp.).

A inclusão de Hippocrateoideae como subfamília de Celastraceae é reconhecida por todos os sistemas de classificação de angiospermas propostos nos últimos anos (Takhtajan 1997; Judd et al. 1999; APG 2003), em contraste com abordagens anteriores, onde era ora incluída (Gunn et al. 1992), ora excluída (Cronquist 1981). Neste trabalho, foram adotadas as propostas atuais que reconhecem o grupo como subfamília Hippocrateoideae de Celastraceae.

A delimitação dos gêneros na região Neotropical é notoriamente controversa, variando de dois, Salacia

\footnotetext{
1 Parte da Dissertação de Mestrado da primeira Autora, desenvolvida na Universidade Federal de Viçosa

2 Universidade Federal de Minas Gerais, Rua Henrique Burnier 160, Apto. 503, Bairro Grajaú, CEP 30430-740, Belo Horizonte, MG, Brasil

3 Universidade Federal de Viçosa, Departamento de Biologia Vegetal

4 Universidade Federal de Minas Gerais, Departamento de Botânica

5 Autor para correspondência: sandra.3@brfree.com.br
} 
e Hippocratea (Peyritsch 1878; Robson 1965), a 17 (Miers 1872). Neste trabalho é seguido Smith (1940), que reconheceu três gêneros segregados de Salacia L. - Cheiloclinium Miers, Peritassa Miers, e Tontelea Aublet - incluídos na tribo Salacieae com as espécies extra-neotropicais dos gêneros Salacighia Loesener e Thyrsosalacia Loesener (Mennega 1997); e sete gêneros segregados de Hippocratea L. - Anthodon Ruiz \& Pav., Cuervea Miers, Elachyptera A.C. Sm., Hylenaea Miers, Prionostemma Miers, Pristimera Miers, Semialarium N. Hallé (= Hemiangium A.C. Sm.) - incluídos na tribo Hippocrateae com as espécies extra-neotropicais dos gêneros Apodostigma Wilcz., Arnicratea N. Hallé, Loeseneriella A.C. Sm., Reissantia N. Hallé, Simicratea N. Hallé e Simirestes N. Hallé.

As Hippocrateoideae são constituídas, na sua maioria, por lianas de caule revoluto e, às vezes, arbustos ou árvores de folhas opostas ou, menos comumente alternas; flores pequenas, diclamídeas, 4-meras ou raro 5-meras, monóclinas, frutos secos capsulares e deiscentes, ou drupáceos e sementes sem endosperma (Smith 1940).

Dados moleculares recentes têm confirmado a tendência de inclusão das Hippocrateaceae dentro da família Celastraceae como um agrupamento subgenérico monofilético (APG 2003), enquanto Salacia sensu strictu tem também sido considerado como parafilético (Simmons et al. 2001a; b).

Os estudos anatômicos desenvolvidos com espécies de Hippocrateoideae são escassos. Além das descrições apresentadas por Solereder (1908) e Metcalfe \& Chalk (1979), que reuniram as características anatômicas de relevância taxonômica nas principais famílias das dicotiledôneas, podem ser citados os trabalhos de Den Hartog et al. (1978) que descreveram os caracteres epidérmicos foliares de 89 espécies de Celastraceae; de Osornio \& Engleman (1993; 1994) que estudaram a anatomia do desenvolvimento das sementes de quatro espécies de Hippocratea L. s.l.; de Mennega (1997) que descreveu a anatomia do lenho da subfamília, e de Fernandez et al. (1998) que desenvolveram estudos anatômicos dos órgãos vegetativos de Hippocratea excelsa Mart. ( $\equiv$ Hemiangium excelsum = Semialarium mexicanum (Miers) Mennega).

Os caracteres anatômicos dos órgãos vegetativos das plantas servem como dados adicionais às características morfológicas externas podendo ser usados para resolver problemas taxonômicos (Metcalfe \& Chalk 1983). A importância dos caracteres anatômicos para a taxonomia de Celastraceae foi comprovada por Smith \& Robinson (1971), Den Hartog et al. (1978) e Mennega (1997). Smith \& Robinson (1971) utilizaram características epidérmicas foliares na definição das espécies de Hippocrateaceae ocorrentes em Santa Catarina. Den Hartog et al. (1978) sustentaram a ampliação do conceito da família Celastraceae com base nos tipos de estômatos e de células cristalíferas na epiderme foliar de Celastraceae sensu latu. Mennega (1997) propõe a divisão de Hippocrateoideae em dois grupos distintos de acordo com a anatomia do lenho; estes grupos são: Salacieae de um lado e Hippocrateae, Helictonemeae e Campylostemoneae do outro.

O Estudo da palinotaxonomia de espécies brasileiras de Hippocrateaceae (Gonçalves-Esteves \& Melhem 1998; 2000; 2002; 2004) mostrou que características dos grãos de pólen como: o tipo de área apertural, o tipo de ornamentação da exina, a forma e as classes de tamanho; são bons caracteres diagnósticos a nível específico. Estes dados possibilitaram a confecção de chaves polínicas e a separação das diferentes espécies ou grupos de espécies; além de confirmarem a delimitação genérica das Hippocrateaceae da América do Sul. Porém, de acordo com Gonçalves-Esteves \& Melhem (1998; 2000; 2002; 2004) as características dos grãos de pólen de Tontelea Aublet, Salacia L., Peritassa Miers e Cheiloclinium Miers não refletem as divisões infragenéricas propostas por Smith (1940) que baseou-se apenas em características vegetativas e reprodutivas.

Considerando-se as divergências taxonômicas acerca da subfamília Hippocrateoideae e a importância dos estudos anatômicos na resolução de problemas taxonômicos, propõe-se a caracterização da anatomia foliar de treze espécies pertencentes a nove gêneros da subfamília Hippocrateoideae. Tal caracterização, tem como objetivo selecionar dados anatômicos que possam subsidiar a taxonomia dos diferentes gêneros, além de contribuir com possíveis características para a identificação das espécies.

\section{Material e métodos}

Foram estudadas 13 espécies de Hippocrateoideae: Anthodon decussatum Ruiz \& Pav., Cheiloclinium cognatum (Miers) A.C. Sm., C. serratum (Cambess.) A.C. Sm., Cuervea crenulata Mennega, Elachyptera micrantha (Cambess.) A.C. Sm., Hippocratea volubilis L., Peritassa flaviflora A.C. Sm., P. mexiae A.C. Sm., Pristimera nervosa (Miers) A.C. Sm., Salacia 
crassifolia (Mart. ex Schult.) G. Don, Tontelea fluminensis (Peyr.) A.C. Sm., T. leptophylla A.C. Sm. e T. miersii (Peyr.) A.C. Sm., representando quase todos os gêneros ocorrentes no sudeste do Brasil, exceto por Semialarium N. Hallé.

Folhas de todas as espécies utilizadas neste estudo foram obtidas à partir de coletas em diversas localidades: Anthodon decussatum Ruiz \& Pav. foi coletado na Reserva Particular do Patrimônio Nacional

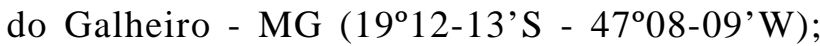
Cheiloclinium cognatum, C. serratum, Elachyptera micrantha, Peritassa flaviflora, P. mexiae, Pristimera nervosa, Tontelea fluminensis, T. leptophylla e T. miersii foram coletadas no Parque Estadual do Rio

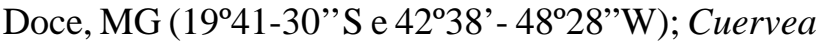
crenulata foi coletada em Salto da Divisa, MG (1603'45,4'S e 4003'30,7'W); Hippocratea volubilis foi coletada na Estação Ecológica da Universidade Federal de Minas Gerais (1952'10'S e 4358'20'W); e Salacia crassifolia foi coletada no Parque Estadual

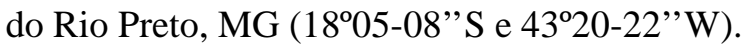

Visando verificar variações estruturais na expressão dos caracteres anatômicos, amostras provenientes de localidades distintas, daquelas inicialmente coletadas, foram retiradas de exsicatas do Herbário do Departamento de Botânica Universidade Federal de Minas Gerais (BHCB). Dessa forma, todas as espécies analisadas foram comparadas com material herborizado; com exceção de Cuervea crenulata devido à ausência de material disponível no BHCB (Tab. 1).

Folhas completamente expandidas foram fixadas em F.A.A. ${ }_{70}$ e posteriormente estocadas em álcool etílico $70 \%$ (Johansen 1940). Na região mediana da lâmina foliar, foram retiradas amostras da nervura principal e da região entre a nervura principal e a margem. Para a confecção de lâminas permanentes, as porções do limbo e do pecíolo foram desidratadas em série butílica (Johansen 1940) e incluídas em parafina histológica. Cortes transversais foram efetuados em micrótomo rotativo LEICA (modelo RM 2155), corados em fucsina básica e azul de astra, sendo posteriormente montados segundo técnicas usuais de anatomia vegetal (Kraus \& Arduin 1997).

Para estudo das características da epiderme, amostras da região mediana do limbo foram submetidas a dissociação utilizando uma solução 1:1 de ácido acético glacial e peróxido de hidrogênio P.A. (Kraus \& Arduin 1997). Posteriormente, as epidermes foram coradas com fucsina básica e azul de astra e montadas, entre lâmina e lamínula, utilizando gelatina glicerinada. Para a caracterização e denominação do tipo de estômatos foram usadas as definições propostas por Den Hartog et al. (1978).

Amostras da região mediana da lâmina e do pecíolo foram submetidas à maceração utilizando-se o método de Jeffrey (Foster 1949). Após a maceração, o material foi corado com fucsina básica e azul de astra e montado em gelatina glicerinada.

O material proveniente de exsicatas foi reidratado (Smith \& Smith 1942) e submetido ao mesmo padrão de amostragem citado para o material fixado. Os cortes foram feitos em micrótomo de mesa, clarificados com água sanitária comercial diluída a $20 \%$, corados com fucsina e azul de astra e montados em gelatina glicerinada.

As análises anatômicas e a documentação fotográfica referentes a microscopia de luz foram realizadas em fotomicroscópio Olympus AX 70 com sistema U-Photo.

\section{Resultados}

Pecíolo - Os pecíolos de todas as amostras analisadas possuem epidermes unisseriadas (Fig. 1). Em Pristimera nervosa ocorrem idioblastos epidérmicos, geralmente aos pares, que contêm monocristais prismáticos (Fig. 2).

A presença de cristais de oxalato de cálcio nos tecidos parenquimáticos do pecíolo e da lâmina foliar é um caráter comum a todas as espécies analisadas. $\mathrm{Na}$ maioria das espécies, os cristais estão na forma de drusas, mas em Cheiloclinium cognatum, Elachyptera micrantha e Pristimera nervosa ocorrem também na forma de monocristais prismáticos (Fig. 3).

Em Cheiloclinium cognatum, Peritassa flaviflora, P. mexiae, Salacia crassifolia, Tontelea fluminensis, T. leptophylla e $T$. miersii estão presentes braquiesclereídes dispersos no parênquima cortical. Estes braquiesclereídes são mais freqüentes na porção apical do pecíolo (ou base foliar) (Fig. 4).

Em Cheiloclinium cognatum, C. serratum e Hippocratea volubilis foi verificada a presença de uma substância pegajosa tanto no pecíolo quanto na lâmina foliar. A análise de Cheiloclinium serratum e Hippocratea volubilis revelou a presença de laticíferos os quais concentram-se ao redor do sistema vascular do pecíolo e da lâmina foliar (Fig. 5, 6). Em Cheiloclinium cognatum, os laticíferos não foram observados.

Os feixes vasculares do pecíolo de todas as espécies estudadas são colaterais, porém a conformação do 
Tabela 1. Amostras analisadas de Hippocrateoideae (Celastraceae) no sudeste do Brasil.

\begin{tabular}{|c|c|c|}
\hline Espécie & Amostras analisadas & Local da coleta \\
\hline \multirow[t]{3}{*}{ Anthodon decussatum Ruiz \& Pav. } & J.A. Lombardi 3190 & Perdizes, MG, RPPN do Galheiro (CEMIG)* \\
\hline & L.C. Bernacci 969 & Cardoso, SP \\
\hline & A. Salino 3767. & Jequeri, MG \\
\hline \multirow[t]{3}{*}{ Cheiloclinium cognatum (Miers) A.C. Sm. } & J.A. Lombardi 2869 & Timóteo, MG, Parque Estadual do Rio Doce* \\
\hline & N.M. Ivanauskas 1614 & Nova Xavantina, MT \\
\hline & I. Cordeiro, et al. 732 & Itains, SP, Estação Ecológica Juréia \\
\hline \multirow[t]{3}{*}{ Cheiloclinium serratum (Cambess.) A.C. Sm. } & Lombardi 3939 & Timóteo, MG, Parque Estadual do Rio Doce* \\
\hline & M.M. Arbo 7681 & Maracás, BA \\
\hline & G. Hatschbach \& J.M. Silva 58527 & Antonina, PR \\
\hline Cuervea crenulata Mennega & J.A. Lombardi et al. 5334 & Salto da Divisa, $\mathrm{MG}^{*}$ \\
\hline \multirow[t]{3}{*}{ Elachyptera micrantha (Cambess.) A.C. Sm. } & Lombardi 3927 & Timóteo, MG, Parque Estadual do Rio Doce* \\
\hline & M.P. Costa et al. 61 & Itains, SP, Estação Ecológica da Juréia \\
\hline & G. Hatschbach \& J.M. Silva 5773 & Guaraquiçaba, PR \\
\hline \multirow[t]{2}{*}{ Hippocratea volubilis $\mathrm{L}$. } & J.A. Lombardi 1480 & $\begin{array}{l}\text { Belo Horizonte, MG, Estação Ecológica da } \\
\text { UFMG* }\end{array}$ \\
\hline & A. Salino 4725 & Pedra Azul, MG \\
\hline \multirow[t]{3}{*}{ Peritassa flaviflora A.C. Sm. } & J.A. Lombardi 3929 & Timóteo, MG, Parque Estadual do Rio Doce* \\
\hline & J.A. Lombardi 3191 & Perdizes, MG, RPPN do Galheiro (CEMIG) \\
\hline & A. Salino 3761 & Jequeri, MG \\
\hline \multirow[t]{3}{*}{ Peritassa mexiae A.C. Sm. } & J.A. Lombardi 1305 & Timóteo, MG, Parque Estadual do Rio Doce* \\
\hline & L. Rossi et al. 1068 & Itains, SP, Estação Ecológica da Juréia \\
\hline & J. Gomes 285 & Caratinga, MG, Estação Biológica de Caratinga \\
\hline \multirow[t]{2}{*}{ Pristimera nervosa (Miers) A.C. Sm. } & J.A. Lombardi 3346 & Timóteo, MG, Parque Estadual do Rio Doce* \\
\hline & G. Hatschbach et al. 62323 & Cáceres, MT \\
\hline \multirow[t]{3}{*}{ Salacia crassifolia (Mart. ex Schult.) G. Don } & J.A. Lombardi 3013 & São Gonçalo do Rio Preto, MG, PERP* \\
\hline & A.A. Azevedo s.n. (BHCB 48737) & Brasilândia de Minas, MG \\
\hline & Melo et al. 803 & Planaltina, DF \\
\hline \multirow[t]{3}{*}{ Tontelea fluminensis (Peyr.) A.C. Sm. } & J.A. Lombardi 2876 & Timóteo, MG, Parque Estadual do Rio Doce* \\
\hline & F. Toledo et al. s.n. (BHCB 19323) & Caratinga, MG, Estação Biológica de Caratinga \\
\hline & Frazão s.n. (BHCB 34462) & Rio de Janeiro, RJ \\
\hline \multirow[t]{3}{*}{ Tontelea leptophylla A.C. Sm. } & J.A. Lombardi 2868 & Timóteo, MG, Parque Estadual do Rio Doce* \\
\hline & S.A.P. Godoy et al. 609 & São Paulo, SP \\
\hline & H.C. de Lima et al. 4120 & Caratinga, MG, Estação Biológica de Caratinga \\
\hline \multirow[t]{4}{*}{ Tontelea miersii A.C. Sm. } & L.V. Costa et al. s.n. (BHCB 30683) & Timóteo, MG, Parque Estadual do Rio Doce* \\
\hline & J. A. Lombardi et al. 2386 & Caratinga, MG, Estação Biológica de Caratinga \\
\hline & E.P. Heringer 1825 & Coronel Pacheco, MG \\
\hline & Sem coletor (BHCB 37607) & Laranjal, MG \\
\hline
\end{tabular}

*Amostras que foram coletadas e fixadas em F.A.A.70, o restante corresponde às amostras obtidas no BHCB.

sistema vascular na região mediana é variável entre os diferentes gêneros e espécies. O sistema vascular com a conformação de um arco com as extremidades convolutas foi o padrão mais freqüente tendo sido observado em Anthodon decussatum, Cheiloclinium cognatum, $C$. serratum, Cuervea crenulata, Elachyptera micrantha, Hippocratea volubilis, Peritassa flaviflora, Tontelea leptophylla e T. fluminensis (Fig. 7). Em Peritassa mexiae o sistema vascular do pecíolo também possui esta conformação geral; contudo, o arco vascular desta espécie apresenta reentrâncias em todo o seu contorno (Fig. 8). Em Pristimera nervosa, o sistema vascular também tem a conformação de um arco com as extremidades convolutas e ainda possui dois feixes adaxiais isolados (Fig. 9). Em Salacia crassifolia, mantém-se o mesmo padrão presente em Pristimera nervosa, porém há um número variável de feixes vasculares adaxiais (Fig. 10). Em Tontelea miersii, o sistema vascular do pecíolo, em contraste com as outras duas espécies estudadas deste mesmo gênero, forma um círculo colateral com um feixe vascular na região central, correspondente à medula (Fig. 11).

Lâmina foliar - O contorno das paredes anticlinais das células epidérmicas varia entre as espécies estudadas. Em Cheiloclinium cognatum, $C$. serratum, Peritassa 

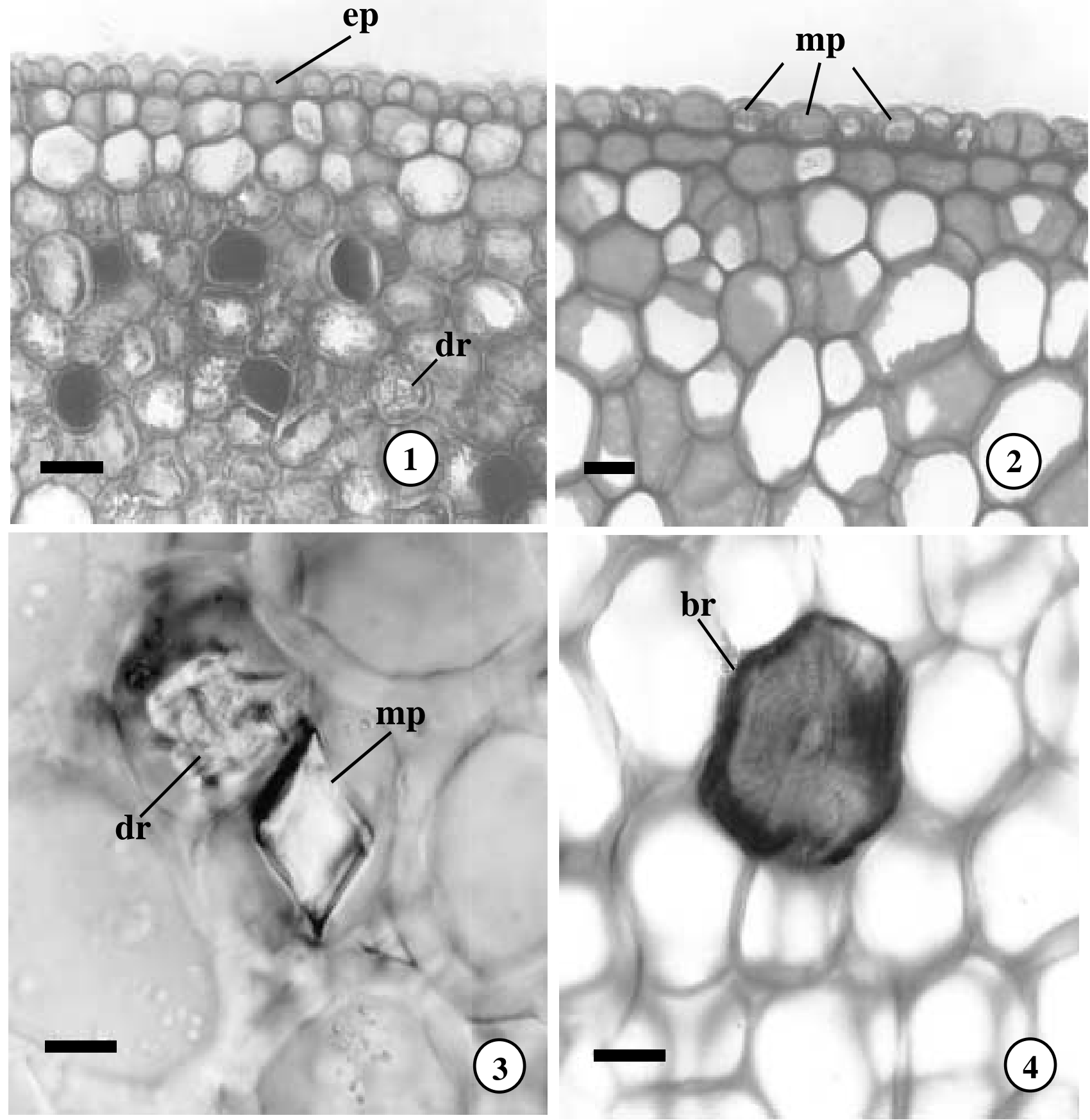

Figuras 1-4. Pecíolos em secções transversais. 1. Epiderme unisseriada de Cuervea crenulata Mennega em detalhe. 2. Idioblastos epidérmicos contendo monocristais prismáticos em Pristimera nervosa (Miers) A.C. Sm. 3. Idioblastos contendo drusas e monocristais prismáticos na região do parênquima cortical de Cheiloclinium cognatum (Miers) A.C. Sm. 4. Braquiesclereíde no parênquima cortical de Cheiloclinium cognatum (Miers) A.C. Sm. Barra $=20 \mu \mathrm{m}(1,2) ; 8 \mu \mathrm{m}$ (3); $45 \mu \mathrm{m}$ (4). br - braquiesclereíde; dr - drusas; ep - epiderme; $\mathrm{mp}$ - monocristais prismáticos. 
flaviflora, P. mexiae e Cuervea crenulata as paredes anticlinais são sinuosas (Fig. 12). Nas demais espécies, as paredes anticlinais das células da epiderme apresentam-se retas como observado em Pristimera nervosa (Fig. 13).

Em Cuervea crenulata, a cutícula sobre a epiderme adaxial possui ornamentações cuticulares visíveis em microscopia de luz. Tal ornamentação consiste em dobras estriadas com orientação aleatória (Fig. 14). Dentre as espécies estudadas, Cuervea crenulata é a única a apresentar este caráter.

A maioria das espécies de Hippocrateoideae estudadas são hipoestomáticas. Em Anthodon decussatum, Pristimera nervosa e Hippocratea volubilis foi verificada a presença de estômatos também na face adaxial da folha, sendo estes restritos à região da nervura mediana (Fig. 15 a 20). Em Hippocratea volubilis os estômatos localizados na face adaxial foram também observados sobre as nervuras laterais de maior calibre (Fig. 21).

O tipo de estômato variou entre as espécies e gêneros estudados. $\mathrm{O}$ tipo de estômato mais freqüente
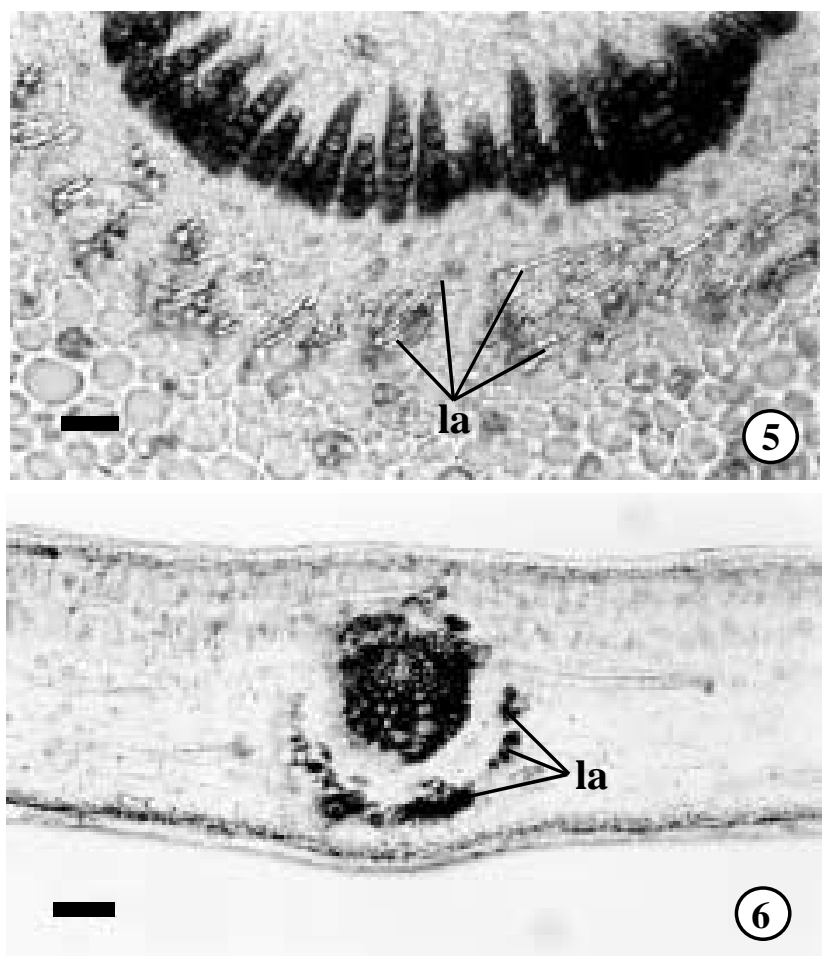

Figuras 5-6. Laticíferos. 5. Corte transversal do pecíolo de Hippocratea volubilis L. evidenciando laticíferos ao redor do sistema vascular. 6. Corte transversal da lâmina foliar de Cheiloclinium serratum (Cambess.) A.C. Sm. revelando presença de laticíferos associados às nervuras laterais. Barra $=45 \mu \mathrm{m}$. la - laticíferos. foi o ciclocítico com o número de células subsidiárias variando de quatro a sete. Cheiloclinium cognatum, C. serratum, Cuervea crenulata, Peritassa flaviflora, P. mexiae, Salacia crassifolia e Tontelea miersii possuem estômatos ciclocíticos (Fig. 22, 23). Hippocratea volubilis, Pristimera nervosa e Elachyptera micrantha possuem estômatos laterocíticos com o número de células subsidiárias variando de três a sete (Fig. 24, 25). Tontelea fluminensis, T. leptophylla possuem estômatos anomocíticos (Fig. 26, 27). Em Anthodon decussatum estão presentes estômatos paracíticos e laterocíticos e o número de células subsidiárias varia de duas a quatro (Fig. 28 a 30).

Em corte transversal, nota-se a presença de uma crista cuticular em torno do átrio externo ao ostíolo em todas as amostras estudadas (Fig. 31). Observa-se ainda, que as células subsidiárias dos estômatos de Hippocrateoideae se localizam em um nível interno à epiderme e parcial ou completamente submersas sob as células-guarda (Fig. 31, 32).

A presença de idioblastos cristalíferos na epiderme, em ambas as faces da folha, foi verificada em quatro das espécies estudadas. Em Peritassa flaviflora A.C. Sm. e P. mexiae A.C. Sm., os cristais ocorrem na forma de drusas (Fig. 33). Porém, a freqüência dos cristais não se manteve constante em todas as amostras de Peritassa mexiae analisadas, pois, estavam presentes na amostra J. Gomes 285, mas ausentes nas amostras J.A. Lombardi 1305 e L. Rossi et al. 1068. Em Elachyptera micrantha e Pristimera nervosa, os cristais ocorrem como monocristais prismáticos e apresentaram frequiência constante para todas as amostras analisadas (Fig. 34).

Em seção transversal da lâmina foliar de Anthodon decussatum (Fig. 35), Hippocratea volubilis (Fig. 36) e Pristimera nervosa (Fig. 37) nota-se, na face adaxial, a presença de hipoderme. Esta hipoderme é constituída por uma camada de células aclorofiladas com dimensões maiores que as células epidérmicas. A estrutura do mesofilo variou entre as espécies estudadas. Em Anthodon decussatum, o mesofilo é homogêneo (Fig. 35). Em Cheiloclinium cognatum, C. serratum, Cuervea crenulata, Hippocratea volubilis, Peritassa flaviflora, P. mexiae, Pristimera nervosa, Salacia crassifolia, Tontelea fluminensis, T. leptophylla e T. miersii, o mesofilo é dorsiventral (Fig. 36, 37). Enquanto Elachyptera micrantha possui o mesofilo isobilateral (Fig. 38).

Em Peritassa flaviflora, P. mexiae e Salacia crassifolia foi verificada a presença de esclereídes alongadas que atravessam o mesofilo. Em Peritassa 

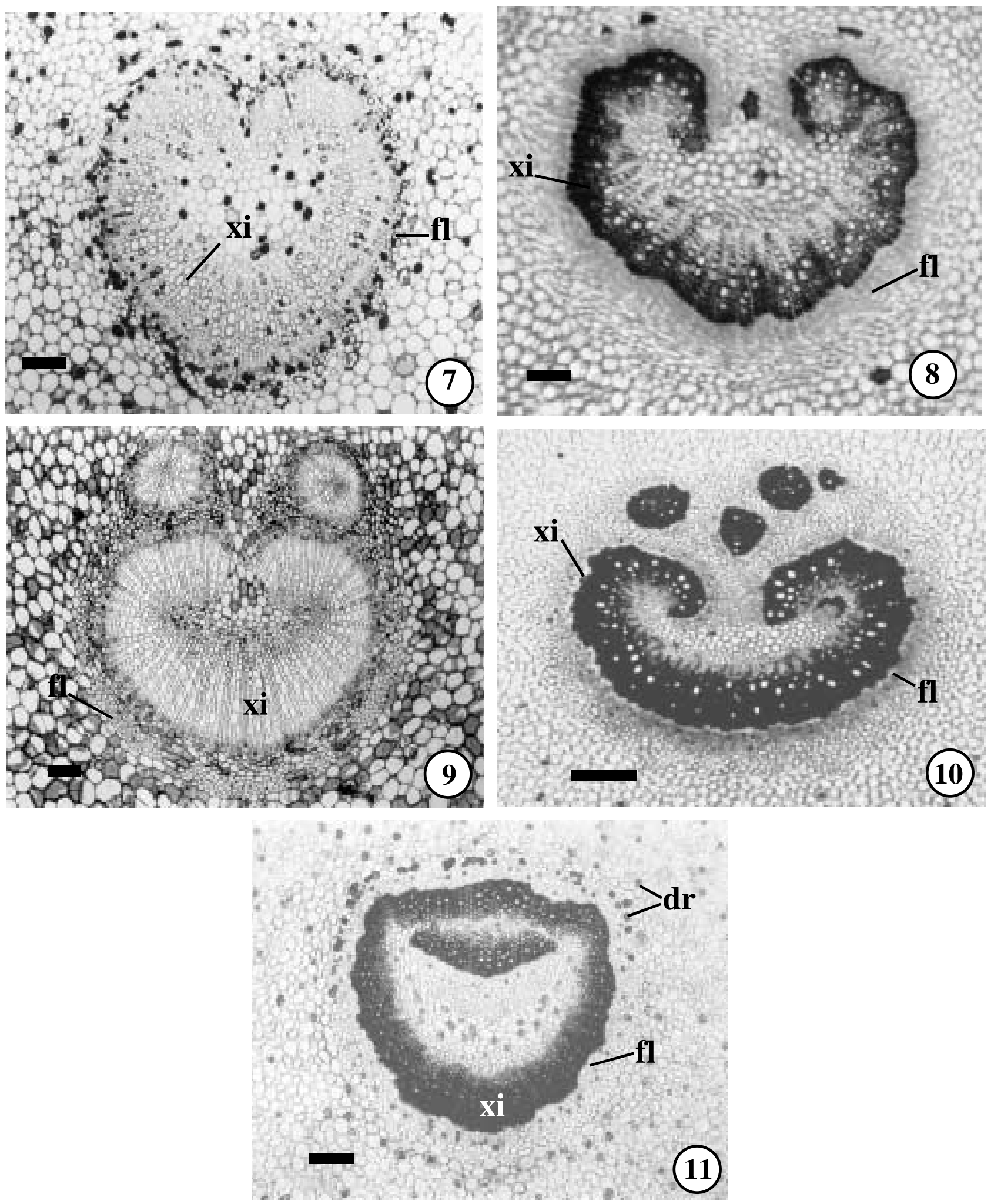

Figuras 7-11. Secções transversais dos pecíolos destacando o tipo de conformação do sistema vascular. 7. Peritassa flaviflora A.C. Sm. 8. Peritassa mexiae A.C. Sm. 9. Pristimera nervosa (Miers) A.C. Sm. 10. Salacia crassifolia (Mart. ex Schult.) G. Don. 11. Tontelea miersii A.C. Sm. Barra $=90 \mu \mathrm{m}(7,8,9,11) ; 220 \mu \mathrm{m}$ (10). dr - drusas; fl - floema; xi - xilema. 
flaviflora e Peritassa mexiae, estas esclereídes estão localizadas sob a epiderme adaxial e aderidas à ela. Em Peritassa flaviflora, as esclereídes possuem protuberâncias em sua extensão e não atravessam completamente o mesofilo, nunca alcançando a epiderme abaxial (Fig. 39, 40). Já em Peritassa mexiae, as esclereídes são mais longas e atravessam todo o mesofilo chegando, inclusive, a atingir a epiderme abaxial (Fig. 41, 42). Em Salacia crassifolia, as
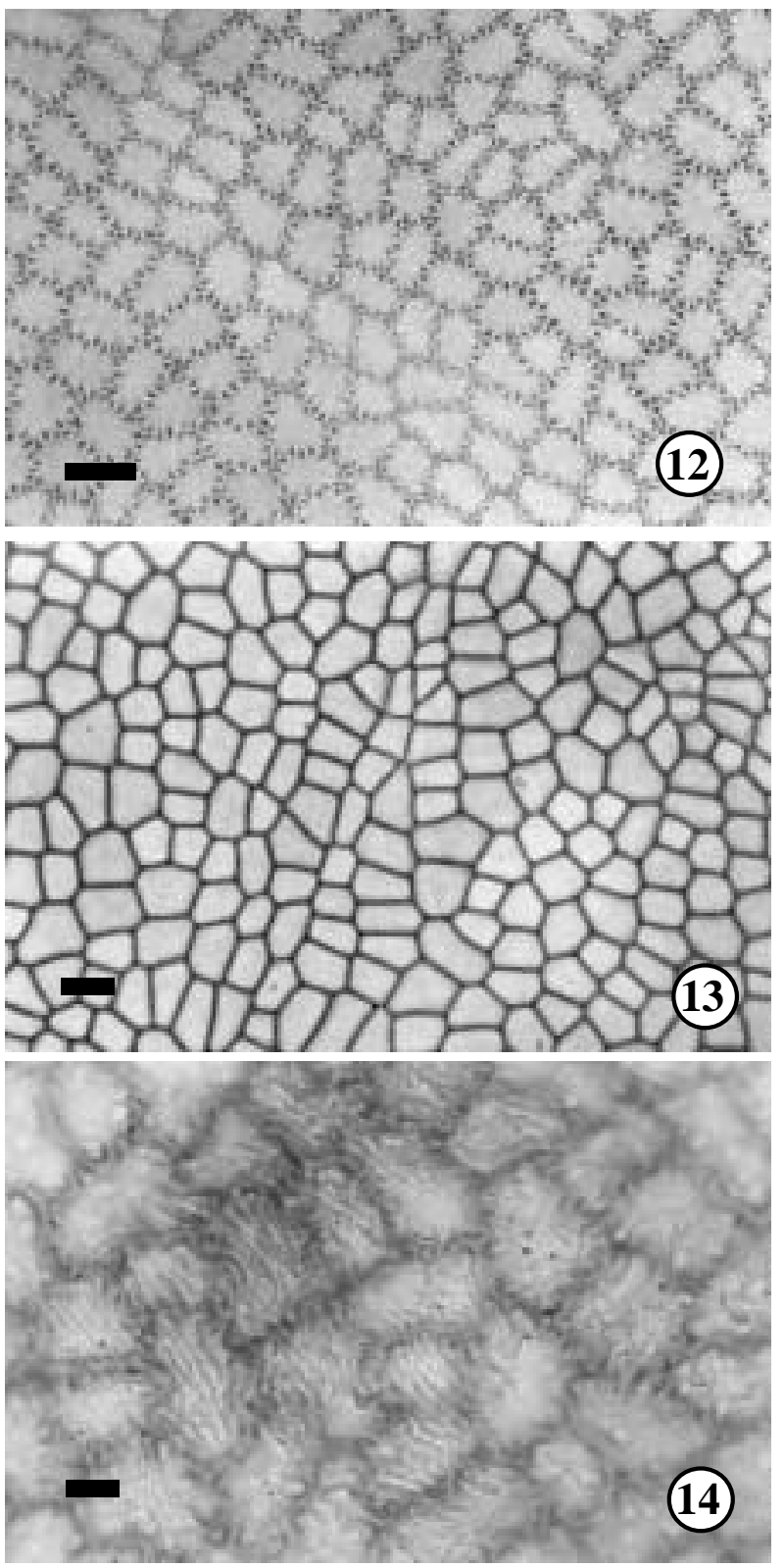

Figuras 12-14. Face adaxial da epiderme das lâminas foliares em vista frontal. 12. Paredes anticlinais sinuosas da epiderme de Cheiloclinium cognatum (Miers) A.C. Sm. 13. Paredes anticlinais retas da epiderme de Tontelea leptophylla A.C. Sm. 14. Ornamentações cuticulares sobre a epiderme de Cuervea crenulata Mennega. Barra $=8 \mu \mathrm{m}(14) ; 20 \mu \mathrm{m}(12,13)$. esclereídes são mais abundantes que nas espécies de Peritassa, além disso, são ramificadas e se apoiam em ambas as faces da folha, tendo como ponto de confluência as nervuras laterais (Fig. 43, 44).

As principais características anatômicas distintivas entre os gêneros e espécies de Hippocrateoideae estudados estão listadas nas Tabelas 2 e 3.

\section{Discussão}

Alguns caracteres anatômicos observados nas espécies estudadas apresentam valor taxonômico e podem ser usados como diagnósticos (Tab. 2 e 3).

Foi observada, tanto no pecíolo quanto na lâmina foliar de algumas espécies, a presença de uma secreção pegajosa que se mostrava evidente no momento de fragmentar o material. No caso de Cheiloclinium cognatum, a secreção foi percebida macroscopicamente, mas a análise dos dados anatômicos não revelou o tipo de estrutura secretora. Em Cheiloclinium serratum e em Hippocratea volubilis, pôde-se identificar laticíferos principalmente associados ao tecido vascular do pecíolo e da lâmina foliar. Metcalfe \& Chalk (1979) já haviam verificado, como característica marcante da então família Hippocrateaceae, a presença de canais laticíferos no caule de algumas espécies, os quais podiam estar presentes também nas folhas de algumas outras. Os autores afirmam também, que algumas células do mesofilo contém um material semelhante a látex, e chamam a atenção para o fato de que apesar dos laticíferos serem característicos para a família, eles não são facilmente visíveis, especialmente se os conteúdos tiverem sido dissolvidos durante a preparação e montagem dos cortes. Estes mesmos autores ainda especificam que em Campylostemon, os laticíferos acompanham os tubos crivados do floema; e que em Hippocratea velutina, o mesofilo contém células de mucilagem. Solereder (1908) também verificou elementos semelhantes a canais laticíferos no caule e na folha de Salacia micrantha (三Tontelea micrantha). Metcalfe \& Chalk (1983) reforçaram a idéia de que as estruturas secretoras e o material secretado por elas são de muito interesse para a anatomia sistemática porque freqüentemente adicionam aparência distintiva aos padrões celulares da planta em que estão presentes. Além disso, a distribuição restrita de algum tipo particular de estrutura secretora fornece um caráter diagnóstico que é freqüentemente bastante valioso.

Dentre os dados anatômicos de valor taxonômico e diagnóstico encontrados, o caráter de mais fácil visualização é a variação na conformação do sistema 

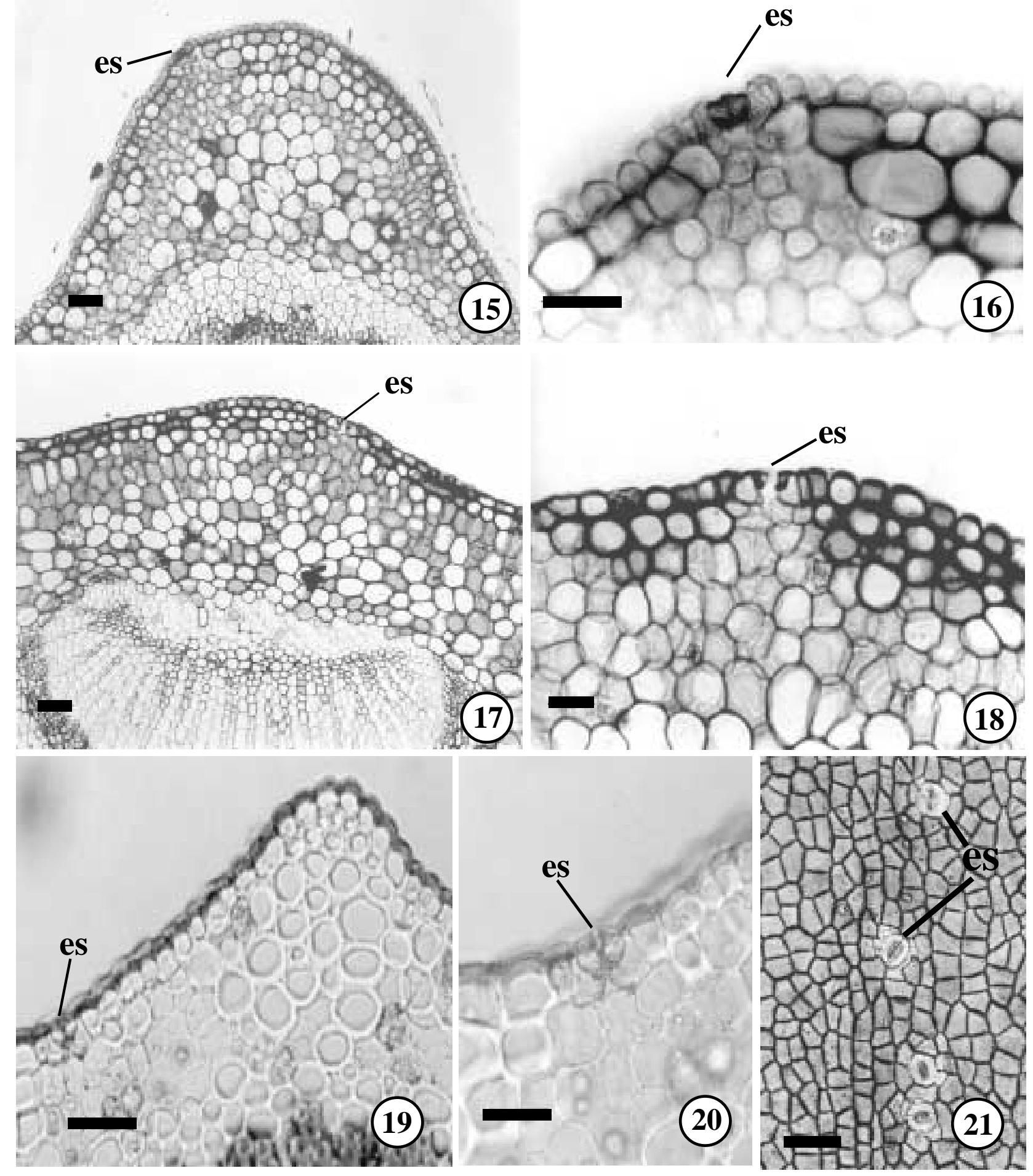

Figuras 15-21. Secção transversal das nervuras medianas indicando presença de estômatos na face adaxial da epiderme (15-20) e vista frontal de estômatos presentes na face adaxial da epiderme sobre uma nervura lateral (21). 15-16. Anthodon decussatum Ruiz \& Pav. 17-18. Pristimera nervosa (Miers) A.C. Sm. 19, 20 e 21. Hippocratea volubilis L. Barra $=45 \mu \mathrm{m}(15,17,19,21) ; 20 \mu \mathrm{m}(16,18,20)$. es - estômatos. 

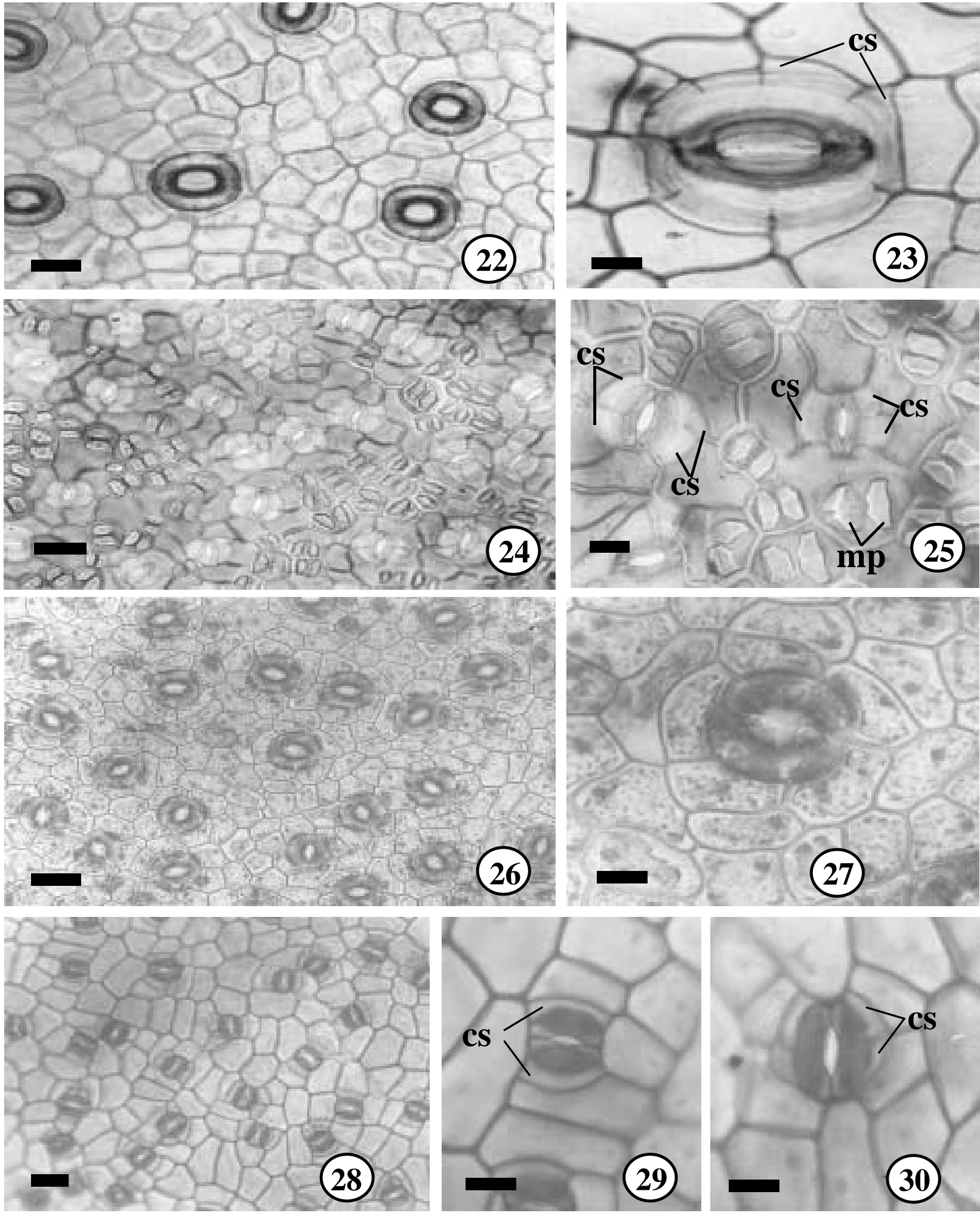

Figuras 22-30. Estômatos em vista frontal. 22-23. Estômatos ciclocíticos na epiderme abaxial de Tontelea miersii A.C. Sm. 24-25. Estômatos laterocíticos na epiderme abaxial de Pristimera nervosa (Miers) A.C. Sm. 26-27. Estômatos anomocíticos na epiderme abaxial de Tontelea fluminensis (Peyr.) A.C. Sm. 28-30. Epiderme abaxial de Anthodon decussatum Ruiz \& Pav.com estômatos paracíticos (29) e laterocíticos (30). Barra $=45 \mu \mathrm{m}(22) ; 8 \mu \mathrm{m}(23,25,27,29,30) ; 20 \mu \mathrm{m}(24,26,28)$. cs - células subsidiárias, mp - monocristais prismáticos. 
vascular na região mediana do pecíolo. O tipo de conformação do sistema vascular na região mediana do pecíolo pode ser evidenciado até mesmo em campo com a utilização de floroglucinol acidificado e lupa de mão. Este caráter apresentou algumas variações entre as espécies estudadas e revelou ser fixado geneticamente pois se manteve constante em relação aos vários locais de coleta das amostras. Por exemplo, as amostras de Anthodon decussatum que vegetavam em diferentes hábitats como mata decídua (J.A. Lombardi 3190), mata mesófila semi-decídua (L.C. Bernacci 969) e floresta ciliar de encosta (A. Salino 3767), apresentaram todas a mesma conformação de um arco com as extremidades convolutas em seu sistema vascular do pecíolo. Da mesma forma; Hippocratea volubilis, cujas amostras eram provenientes de mata semi-decídua (J.A. Lombardi 1480) e cerradão (A. Salino 4725) também possuíam este mesmo padrão de conformação vascular no pecíolo.

Foram encontradas importantes variações nos caracteres da epiderme da lâmina foliar entre as espécies de Hippocrateoideae estudadas. Smith \& Robinson

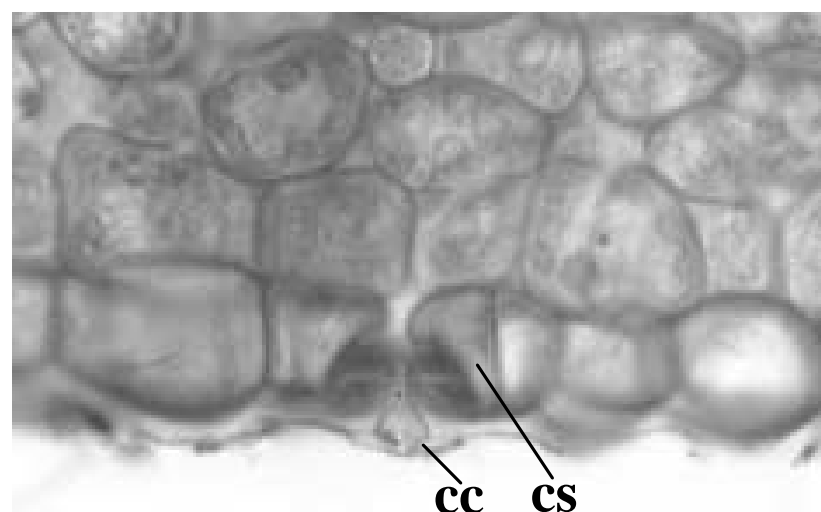

(31)

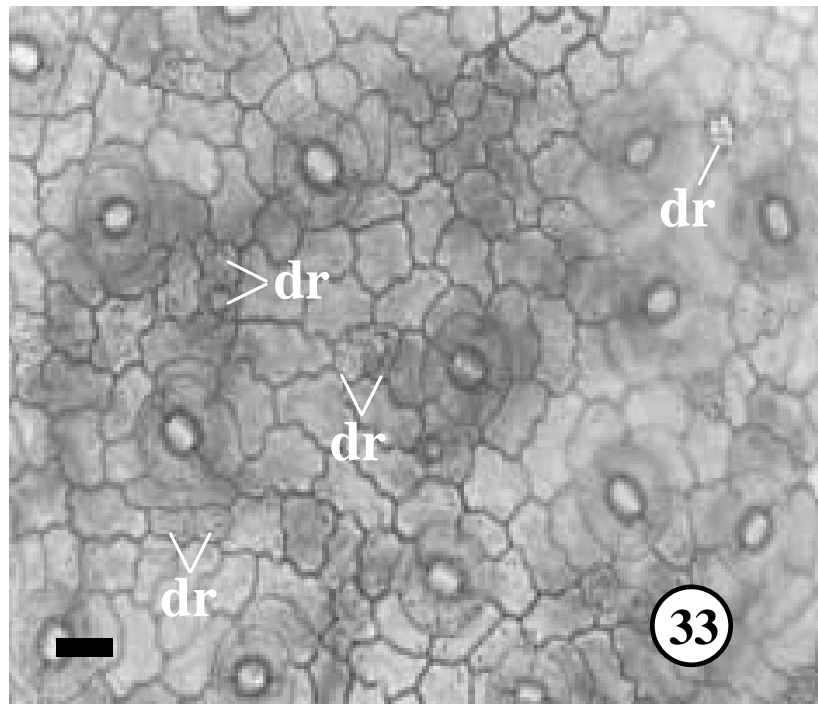

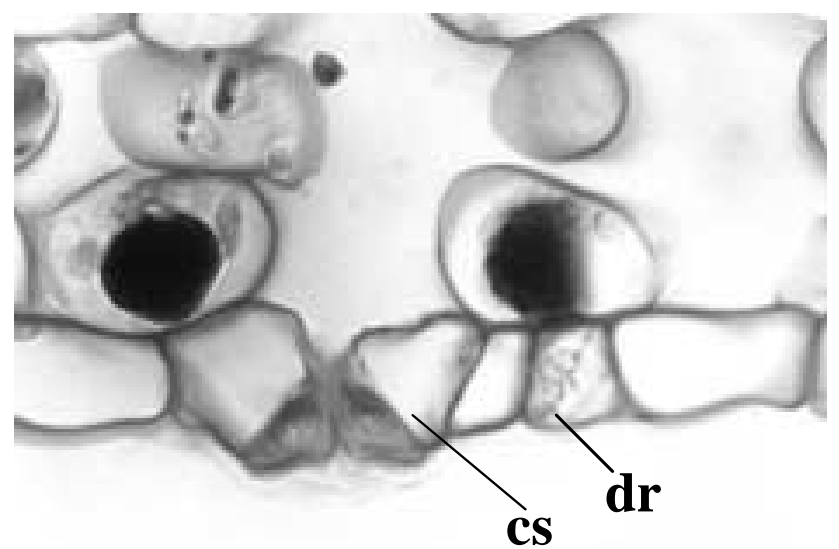

32

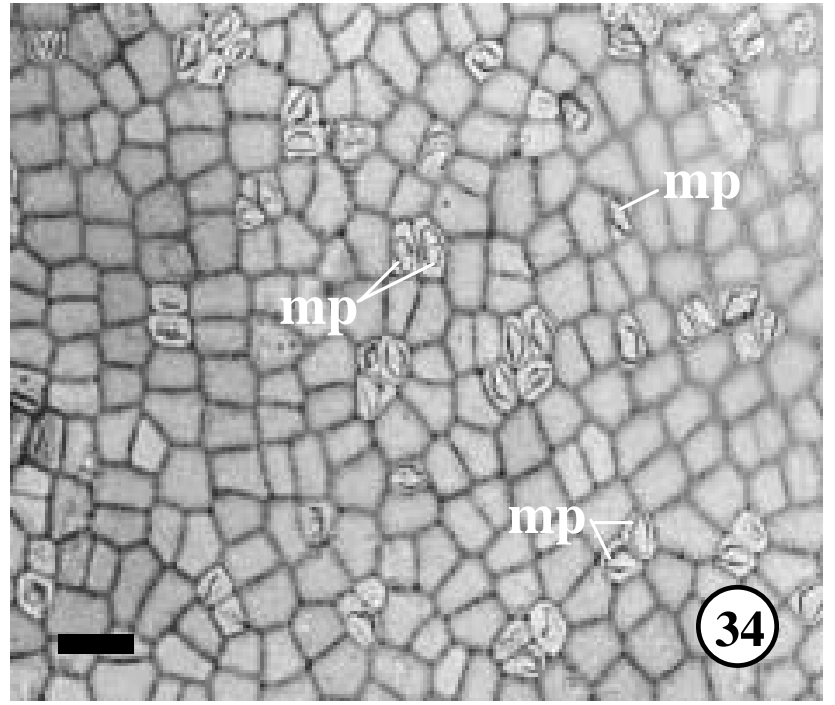

Figuras 31-34. Epidermes em secção transversal (31-32) e em vista frontal (33-34). 31. Face abaxial da epiderme de Anthodon decussatum Ruiz \& Pav. mostrando estômato com células subsidiárias localizadas internamente às células-guarda e crista cuticular em torno do átrio externo ao ostíolo. 32. Face abaxial da epiderme de Peritassa flaviflora A.C. Sm. com células subsidiárias internas às células-guarda e crista cuticular. 33. Idioblastos cristalíferos na forma de drusas na face abaxial da epiderme de Peritassa flaviflora A.C. Sm. 34. Idioblastos cristalíferos na forma de monocristais prismáticos na face adaxial da epiderme de Elachyptera micrantha $($ Cambess. $)$ A.C. Sm. Barra $=8 \mu$ m (31-32); $20 \mu \mathrm{m}$ (33); $45 \mu \mathrm{m}$ (34). cs - célula subsidiária; cc - crista cuticular; dr - drusa; mp - monocristal prismático. 
(1971) utilizaram caracteres da epiderme das espécies de Hippocrateoideae ocorrentes em Santa Catarina como critério adicional na sua definição das espécies.

Em Cuervea crenulata foi verificada a presença de ornamentação cuticular visível em microscopia de luz. Metcalfe \& Chalk (1979) e Barthlott (1981) concordaram ao afirmar que ornamentações cuticulares podem servir como excelentes características diagnósticas, mas seu significado sistemático para delimitação de categorias acima do nível de espécie é um tanto limitado. Fontenelle et al. (1994) utilizaram padrões de estriações cuticulares para auxiliar na identificação das onze espécies de Eugenia estudadas. É provável, portanto, que a investigação da ornamentação cuticular de outras espécies de Cuervea forneça dados valiosos para a taxonomia do gênero. Além disso, dentre os nove gêneros analisados no presente trabalho, apenas Cuervea possui ornamentações cuticulares, consistindo assim num caráter distintivo importante.

O contorno das paredes anticlinais das células epidérmicas variou entre reto a até bastante ondulado.
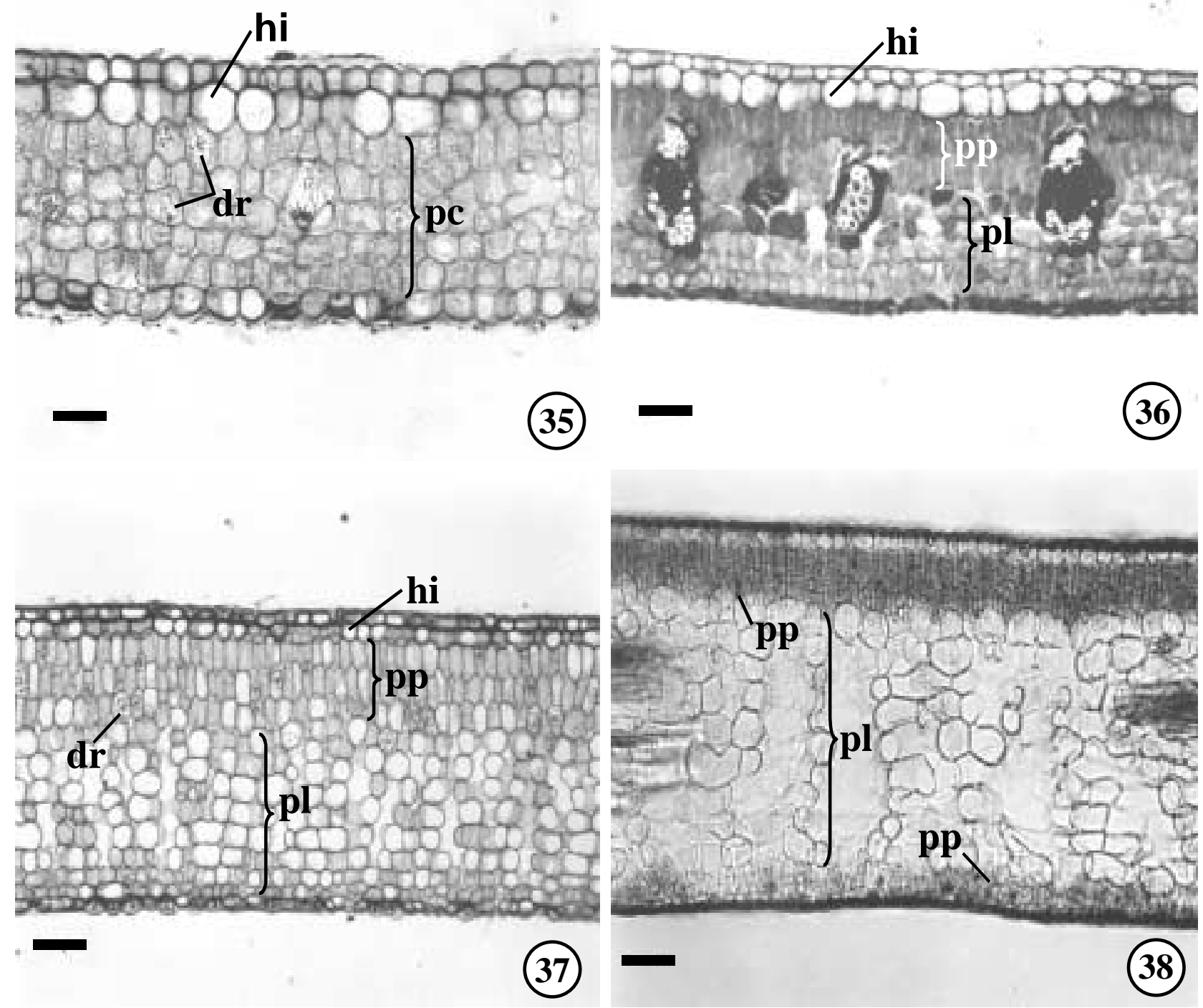

Figuras 35-38. Lâminas foliares em secção transversal. 35. Anthodon decussatum Ruiz \& Pav. mostrando presença de hipoderme e mesofilo homogêneo. 36. Mesofilo dorsiventral e hipoderme de Hippocratea volubilis L. 37. Pristimera nervosa (Miers) A.C. Sm. com hipoderme e mesofilo dorsiventral. 38. Mesofilo isobilateral de Elachyptera micrantha (Cambess.) A.C. Sm. Barra = $40 \mu \mathrm{m}$. dr - drusas; hi - hipoderme; pc - parênquima clorofiliano; pl - parênquima lacunoso; pp - parênquima paliçádico. 

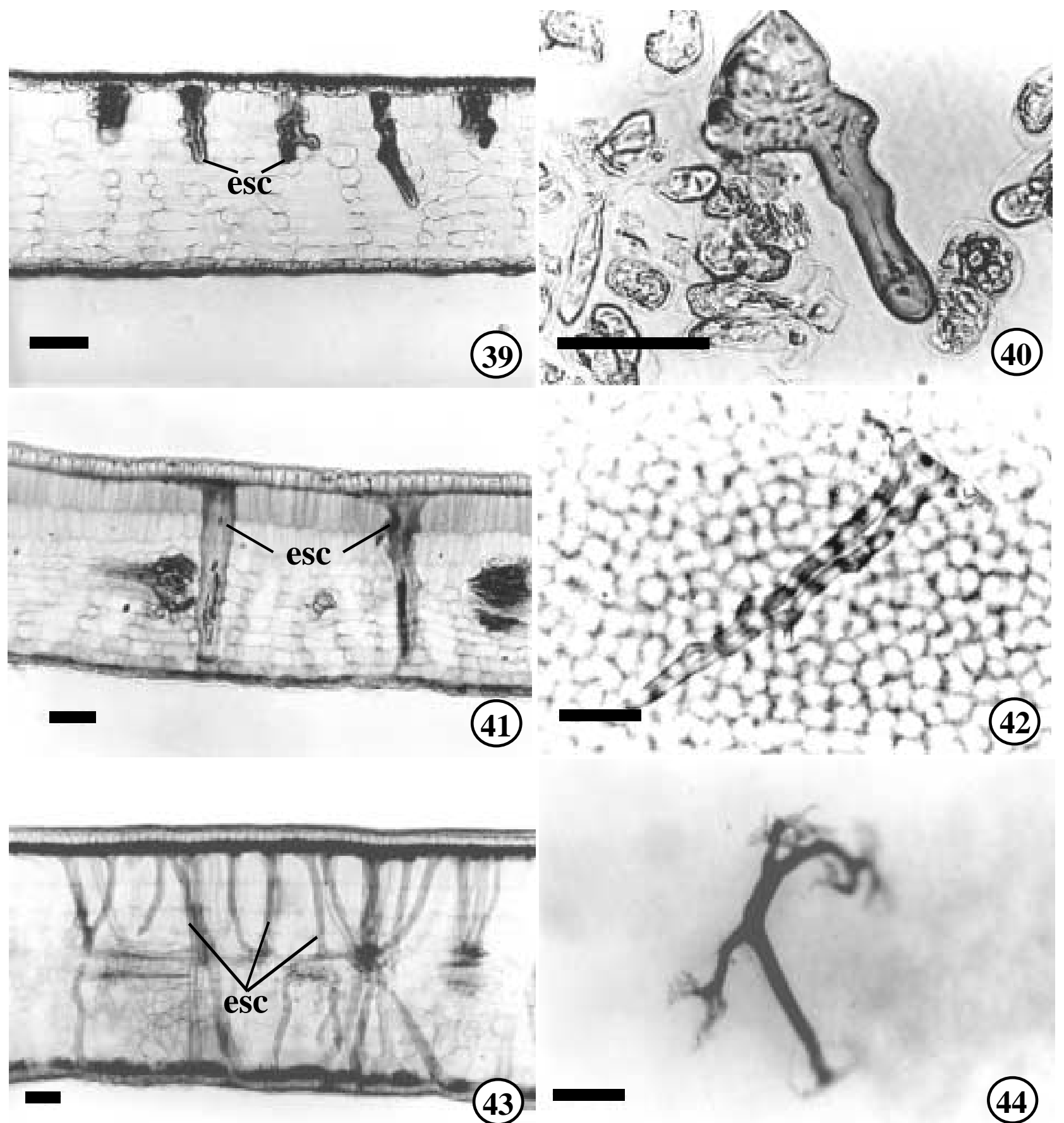

Figuras 39-44. Esclereídes alongados da lâmina foliar vistos em secção transversal (39, 41, 43) e em macerados (40, 42, 44). 39. Esclereídes alongados de Peritassa flaviflora A.C. Sm. que não atravessam totalmente o mesofilo. 40. Esclereíde de Peritassa flaviflora A.C. Sm. visto isoladamente. 41. Esclereídes alongados de Peritassa mexiae A.C. Sm. que atravessam completamente o mesofilo e alcançam a face abaxial da epiderme. 42. Esclereíde de Peritassa mexiae A.C. Sm. 43. Salacia crassifolia (Mart. ex Schult.) G. Don com esclereídes ramificados e abundantes. 44. Esclereíde ramificado de Salacia crassifolia (Mart. ex Schult.) G. Don. Barra $=50 \mu \mathrm{m}$. esc - esclereíde. 
Tabela 2: Variações na conformação do sistema vascular do pecíolo das espécies de Hippocrateoideae estudadas.

Conformação do sistema vascular Espécies

\begin{tabular}{lllllllllllll}
\hline 1 & 2 & 3 & 4 & 5 & 6 & 7 & 8 & 9 & 10 & 11 & 12 & 13
\end{tabular}<smiles>[C]1CCCCC1</smiles><smiles>OC1CCCCCC1</smiles>

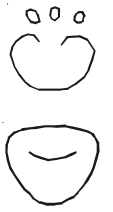

1. Anthodon decussatum Ruiz \& Pav., 2. Cheiloclinium cognatum (Miers) A.C. Sm., 3. Cheiloclinium serratum (Cambess.) A.C. Sm., 4. Cuervea crenulata Mennega, 5. Elachyptera micrantha (Cambess.) A.C. Sm., 6. Hippocratea volubilis L., 7. Peritassa flaviflora A.C. Sm., 8. Peritassa mexiae A.C. Sm., 9. Pristimera nervosa (Miers) A.C. Sm., 10. Salacia crassifolia (Mart. ex Schult.) G. Don, 11. Tontelea fluminensis (Peyr.) A.C. Sm., 12. Tontelea leptophylla A.C. Sm. e 13. Tontelea miersii (Peyr.) A.C. Sm. $+=$ presente; - = ausente.

Tabela 3. Principais características anatômicas distintivas entre as espécies de Hippocrateoideae estudadas.

Caracteres

Espécies

\begin{tabular}{lllllllllllll}
\hline 1 & 2 & 3 & 4 & 5 & 6 & 7 & 8 & 9 & 10 & 11 & 12 & 13
\end{tabular}

Ornamentação cuticular na epiderme adaxial

Paredes anticlinais das células epidérmicas retas

Paredes anticlinais das células epidérmicas onduladas

Drusas na epiderme

Monocristais prismáticos na epiderme

Estômatos na epiderme adaxial da nervura mediana

Estômato anomocítico

Estômato ciclocítico

Estômato laterocítico

Estômato paracítico

Mesofilo dorsiventral

Mesofilo isobilateral

Mesofilo homogêneo

Hipoderme na lâmina foliar

Drusas nos tecidos parenquimáticos

Monocristais prismáticos nos tecidos parenquimáticos

Laticíferos

Braquiesclereídes no pecíolo

Esclereídes alongados na lâmina foliar

$\begin{array}{lllllllllllll}- & - & - & + & - & - & - & - & - & - & - & - & - \\ + & - & - & + & + & + & - & - & + & + & + & + & + \\ - & + & + & - & - & - & + & + & - & - & - & - & - \\ - & - & - & - & - & - & + & +/ & - & - & - & - & - \\ - & - & - & - & + & - & - & - & + & - & - & - & - \\ + & - & - & - & - & - & + & - & - & + & - & - & - \\ - & - & - & - & - & - & - & - & - & - & + & + & - \\ - & + & + & + & - & - & + & + & - & + & - & - & + \\ + & - & - & - & + & + & - & - & + & - & - & - & - \\ + & - & - & - & - & - & - & - & - & - & - & - & - \\ - & + & + & + & - & + & + & + & + & + & + & + & + \\ - & - & - & - & + & - & - & - & - & - & - & - & - \\ + & - & - & - & - & - & - & - & - & - & - & - & - \\ + & - & - & - & - & + & - & - & + & - & - & - & - \\ + & + & + & + & + & + & + & + & + & + & + & + & + \\ - & + & - & - & + & - & - & - & + & - & - & - & - \\ - & - & + & - & - & + & - & - & - & - & - & - & - \\ - & + & - & + & + & + & + & + & - & + & + & + & + \\ - & - & - & - & - & - & + & + & - & + & - & - & -\end{array}$

1. Anthodon decussatum Ruiz \& Pav., 2. Cheiloclinium cognatum (Miers) A.C. Sm., 3. Cheiloclinium serratum (Cambess.) A.C. Sm., 4. Cuervea crenulata Mennega, 5. Elachyptera micrantha (Cambess.) A.C. Sm., 6. Hippocratea volubilis L., 7. Peritassa flaviflora A.C. Sm., 8. Peritassa mexiae A.C. Sm., 9. Pristimera nervosa (Miers) A.C. Sm., 10. Salacia crassifolia (Mart. ex Schult.) G. Don, 11. Tontelea fluminensis (Peyr.) A.C. Sm., 12. Tontelea leptophylla A.C. Sm., 13. Tontelea miersii A.C. Sm. + = presente; - = ausente, +/- presente ou ausente. 
A sinuosidade da parede deve-se, provavelmente, às tensões ocorridas na folha e ao endurecimento da cutícula durante a diferenciação das células (Appezzato-da-Glória \& Carmello-Guerreiro 2003). Fahn (1990) afirmou que, na maioria das folhas de dicotiledôneas de sombra, as células da epiderme apresentam paredes anticlinais sinuosas. Alguns dados apresentados no presente estudo corroboram esta afirmação; como as amostras de Peritassa mexiae analisadas (J.A. Lombardi 1305; L. Rossi et al. $1068 \mathrm{e}$ J. Gomes 285) que vegetavam em área de mata atlântica e apresentavam paredes anticlinais sinuosas. E, por outro lado, em Salacia crassifolia, cujas amostras analisadas (J.A. Lombardi 3013; A.A. Azevedo s.n. e Melo et al. 803) são todas provenientes de ambiente de cerrado, as paredes anticlinais são retas.

Apesar da sinuosidade das paredes anticlinais das células epidérmicas ser um caráter bastante influenciado pelo ambiente (Metcalfe \& Chalk 1979); em todas as espécies analisadas, esta característica se manteve constante independentemente do local de coleta da amostra. Por exemplo, Peritassa flaviflora teve amostras analisadas de indivíduos que habitavam ambiente de mata seca decídua (J.A. Lombardi 3191), de mata atlântica (J.A. Lombardi 3929) e de mata ciliar de encosta (A. Salino 3761). A despeito da localidade de coleta, todas as amostras de Peritassa flaviflora possuíam a parede anticlinal das células epidérmicas sinuosas. Trata-se, portanto, de um dado anatômico distintivo, seguro e de fácil visualização nas epidermes em vista frontal.

Os cristais estavam presentes nos tecidos parenquimáticos e nas epidermes de algumas espécies, na forma de drusas ou monocristais prismáticos. A presença de cristais na família foi registrada por vários autores (Solereder 1908; Smith \& Robinson 1971; Den Hartog et al. 1978; Metcalfe \& Chalk 1979; 1983; Mennega 1983; 1997; Görts-van Rijn \& Mennega 1994; Fernandez et al. 1998). Para Metcalfe \& Chalk (1979), a presença de cristais na epiderme freqüentemente constitui um caráter diagnóstico confiável, especialmente quando em combinação com outros caracteres. Den Hartog et al. (1978) verificaram uma tendência das células cristalíferas estarem mais em evidência em Hippocrateoideae do que em Celastroideae, mas ambas as subfamílias têm representantes com cristais prismáticos ou drusas nas células epidérmicas. Estes autores sugerem que os caracteres epidérmicos foliares como um todo incluindo os cristais - sustentam a ampliação do conceito de Celastraceae.
No caso das Hippocrateoideae analisadas no presente estudo, a ocorrência de cristais na forma de drusas nos tecidos parenquimáticos pode ser considerada uma característica unificadora para o grupo, mas sem valor diagnóstico uma vez que é um caráter comum a todas as espécies estudadas. Contudo, cristais na forma de monocristais prismáticos estão presentes nos tecidos parenquimáticos apenas em Cheiloclinium cognatum, Elachyptera micrantha e Pristimera nervosa podendo assim ser usados na distinção destas espécies. Da mesma forma, idioblastos cristalíferos na epiderme podem ser usados como diagnósticos apenas para Elachyptera micrantha, Peritassa flaviflora e Pristimera nervosa.

Na região da nervura mediana, a presença de estômatos na epiderme adaxial em $A$. decussatum, $H$. volubilis e Pristimera nervosa é um dado relevante para a taxonomia do grupo. De acordo com Metcalfe \& Chalk (1979), existem numerosos exemplos de distribuição estomatal restrita ou especializada que comprovam que esta característica anatômica pode servir como caráter diagnóstico útil devido à localização específica dos estômatos. Den Hartog et al. (1978) já haviam verificado a presença desta característica dentre as espécies de Celastraceae sensu lato examinadas por eles. Houve inclusive, concordância entre estes autores e o presente trabalho, em relação aos gêneros em que este caráter está presente.

Den Hartog et al. (1978) introduziram o termo laterocítico para definir o estômato que possui 3 ou mais células subsidiárias, todas limitando as célulasguarda mas nunca alcançando os seus pólos. Os autores afirmam ainda que, para as Celastraceae, os estômatos do tipo laterocítico são os mais comuns, seguidos pelos tipos paracítico e ciclocítico, e os tipos anisocítico e anomocítico são restritos a um pequeno número de gêneros e espécies. Contudo, nas espécies de Hippocrateoideae aqui estudadas, o tipo de estômato mais freqüente foi o tipo ciclocítico, seguido pelos tipos laterocítico, anomocítico e paracítico. Foi observado também a ocorrência de dois tipos de estômatos na lâmina foliar de Anthodon decussatum.

É necessária uma análise cautelosa para se estabelecer o tipo de estômato em Hippocrateoideae pois, as células subsidiárias se localizam em um nível interno à epiderme e parcial ou completamente submersas sob as células-guarda. Dessa forma, em vista frontal só é possível a visualização de uma pequena porção das paredes das células subsidiárias por transparência sobre a epiderme. Assim, faz-se necessário analisar os estômatos em vista frontal e em 
corte transversal para sua caracterização correta.

Podem ser destacados também, alguns aspectos anatômicos do mesofilo que fornecem dados importantes para a taxonomia do grupo. Observou-se que, para a maioria das espécies de Hippocrateoideae analisadas, o mesofilo é dorsiventral. Entretanto, Anthodon decussatum possui mesofilo homogêneo e Elachyptera micrantha possui mesofilo isobilateral. Além disso, foi constatada a presença de hipoderme somente em Anthodon decussatum, Hippocratea volubilis e Pristimera nervosa. Tanto o tipo de diferenciação do parênquima clorofiliano, quanto a ocorrência de hipoderme têm sido úteis para a taxonomia. Neste sentido, Metcalfe \& Chalk (1979) elaboraram listas de famílias que são caracterizadas por conter determinado tipo de arranjo do parênquima clorofiliano, bem como uma lista de famílias que possuem hipoderme em suas folhas.

Foi verificada a presença de esclereídes de diferentes tipos no grupo estudado. A ocorrência de braquiesclereídes foi constatada nos pecíolos de Cheiloclinium cognatum, Elachyptera micrantha, Peritassa flaviflora, P. mexiae, Salacia crassifolia e nas três espécies de Tontelea estudadas. Além disso, esclereídes alongadas foram vistas nas lâminas foliares de Peritassa flaviflora, P. mexiae e Salacia crassifolia. Franceschinelli \& Yamamoto (1993) verificaram a existência de quatro tipos de esclereídes diferentes em Simarouba (Simaroubaceae) cuja ocorrência não foi influenciada pelas condições ambientais e se mostraram úteis para distinguir as espécies de interesse.

Da mesma forma, no presente estudo, foram analisadas amostras de diferentes localidades; de diferentes tipos vegetacionais, como cerrado (Salacia crassifolia) e mata atlântica atlântica (Peritassa mexiae, Tontelea fluminensis, T. leptophylla e T. miersii); e o tipo de esclereíde se manteve constante para cada espécie. Comprova-se assim o valor taxonômico dos esclereídes para o grupo. É possível, inclusive, separar Cheiloclinium cognatum, que possui braquiesclereídes no pecíolo, de $C$. serratum, que não os possui; bem como, distinguir Peritassa flaviflora de Peritassa mexiae pelo tipo de esclereíde e pela sua disposição no mesofilo. Além disso, a separação dos gêneros estudados é possível pela presença ou ausência de esclereídes no mesofilo e braquiesclereídes no pecíolo.

Com base nos resultados obtidos, foi possível o levantamento de características anatômicas foliares de espécies representativas dos nove gêneros de Hippocrateoideae ocorrentes na região sudeste do
Brasil. Alguns caracteres da anatomia foliar são potencialmente promissores para a taxonomia do grupo quando usados isolados ou em combinação, tais como: o tipo de esclereíde presente no pecíolo ou na lâmina foliar, o tipo de estômato, a conformação do sistema vascular do pecíolo, a sinuosidade das paredes anticlinais das células epidérmicas, a presença de hipoderme, a ocorrência de laticíferos, a presença de idioblastos cristalíferos na epiderme e a diferenciação do mesofilo. Contudo, para se fazer inferências filogenéticas entre os gêneros, ou mesmo para a subfamília como um todo, é necessário que sejam analisados um número maior de espécies por gênero.

\section{Referências bibliográficas}

Appezzato-da-Glória, B.; Carmello-Guerreiro, S. M. (editoras) 2003. Anatomia Vegetal. Viçosa, Editora UFV, Universidade Federal de Viçosa.

APG (The Angiosperm Phylogeny Group). 2003. An update of the Angiosperm Phylogeny Group classification for the orders and families of flowering plants: APG II. Botanical Journal of the Linnean Society 141: 399-436.

Barroso, G.M.; Peixoto, A.L.; Ichasso, C.L.F.; Costa, C.G.; Guimarães E.F. \& Lima H.C. 1984. Sistemática das Angiospermas do Brasil. Viçosa, Universidade Federal de Viçosa, Imprensa Universitária.

Barthlott, W. 1981. Epidermal and seed surface characters of plants: systematic applicability and some evolutionary aspects. Nordic Journal of Botany 1: 345-355.

Cronquist, A. 1981. An integrated system of classification of flowering plants. New York, Collumbian University Press.

Den Hartog, R.M.; Tholen, V. \& Bass, P. 1978. Epidermal characters of the Celastraceae sensu lato. Acta Botanica Neerlandica 27: 355-388.

Fahn, A. 1990. Plant Anatomy. 4 ed. New York, Pergamon Press.

Fernandez, M.G.V.; Morales, J.B. \& Angeles, G. 1998. Anatomical studies on Hippocratea excelsa (Hippocrateaceae ). Acta Botanica Mexicana 43: 7-21.

Fontenelle, G.B.; Costa, C.G. \& Machado, R.D. 1994. Foliar anatomy and micromorphology of eleven species of Eugenia L. (Myrtaceae). Botanical Journal of Linnean Society 115: 111-133.

Foster, A. 1949. Pratical plant anatomy. New York, D. Van Nostrand.

Franceschinelli, E.V. \& Yamamoto, K. 1993. Taxonomic use of leaf anatomical caracters in the genus Simarouba Aublet (Simaroubaceae). Flora 188: 117-124.

Gonçalves-Esteves, V. \& Melhem T.S. 1998. Palinotaxonomia de espécies de brasileiras de Tontelea Aubl. (Hippocrateaceae Juss.). Palinobotânica 7: 33-54. 
Gonçalves-Esteves. V. \& Melhem T.S. 2000. Palinotaxonomia de espécies de brasileiras de Salacia L. (Hippocrateaceae). Revista Brasileira de Botânica 23(4): 425-440.

Gonçalves-Esteves, V. \& Melhem T.S. 2002. Palinotaxonomia de espécies de brasileiras de Peritassa Miers. (Hippocrateaceae Juss.). Acta Botanica Brasilica 16(2): 193-205.

Gonçalves-Esteves, V. \& Melhem T.S. 2004. Palinotaxonomia de espécies de brasileiras de Cheiloclinium Miers. (Hippocrateaceae Juss.). Acta Botanica Brasilica 18(3): 503-512.

Görts-van Rijn, A.R.A. \& Mennega, A.M.W. 1994. Hippocrateaceae. Pp. 110-128. In: A.R.A. Görts-van Rijn. (ed.). Flora of the Guianas 16. Germany, Koeltz Scientific Books.

Gunn, C.R.; Wiersema, J.H.; Ritchie, C.A. \& Kirkbride Jr., J.H. 1992. Families and genera of spermatophytes recognized by the Agricultural Research Service. Technical Bulletin of the United States Department of Agriculture 1796: 1-500.

Hallé, N. 1990. Célastracées (Hippocrateoidées). Pp. 1-247 In: B. Satabie \& P. Morat (eds.). Flore du Cameroun 32. Yaoundé, Ministère de l'Enseignement Supérieur de l'Informatique et de la Recherche Scientifique.

Johansen, D.A. 1940. Plant microtechnique. New York, Mc. Graw Hill Book.

Judd, W.S.; Campbell, C.S.; Kellog, E.A. \& Stevens, P.F. 1999. Plant systematics. A phylogenetic approach. Massachussets, Sunderland, Sinauer Associates.

Kraus, J.E. \& Arduin, M. 1997. Manual básico de métodos em morfologia vegetal. Rio de Janeiro, Universidade Federal Rural do Rio de Janeiro.

Mennega, A.M.W. 1983. Notes on New World Hippocrateeae (Fam. Celastraceae) II - A New Species in Hemiangium. Acta Botanica Neerlandica 32(5/6): 427-430.

Mennega, A.M.W. 1997. Wood Anatomy of the Hippocrateoideae (Celastraceae). IAWA-Journal 18(4): 331-368.

Metcalfe, C.R. \& Chalk, L. 1979. Anatomy of the Dicotyledons: Systematic Anatomy of the Leaf and Stem. v.1. New York, Oxford University Press.
Metcalfe, C.R. \& Chalk, L. 1983. Anatomy of the Dicotyledons: Wood Struture and Conclusion of the General Introduction. v.2. New York, Oxford University Press.

Miers, J. 1872. On the Hippocrateaceae of South America. TransactionsVersão eletrônica do artigo em www.scielo.br/ abb of the Linnean Society of London 28: 319-432.

Osornio, G.E. \& Engleman, E.M. 1993. Anatomía del desarrollo de la semilla de Hippocratea celastroides. Boletin de la Sociedad Botanica de México 53: 43-53.

Osornio, G.E. \& Engleman, E.M. 1994. Anatomía de la semilla de cuatro espécies mexicanas de Hippocratea (Celastraceae). Boletin de la Sociedad Botanica de México 54: 57-67.

Peyritisch, J. 1878. Hippocrateaceae. Pp. 125-164. In: C.F.P. Martius \& A.G. Eichler. Flora Brasiliensis 11(1). Lipsiae, Frid. Fleischer.

Simmons, M.P.; Clevinger, C.C.; Savolainen, V.; Archer, R.H.; Mathews, S. \& Doyle, J.J. 2001a. Phylogeny of the Celastraceae inferred from phytochrome B gene sequence and morphology. American Journal of Botany 88: 313-325.

Simmons, M.P.; Savolainen, V.; Clevinger, C.C.; Archer, R.H. \& Davis, J.I. 2001b. Phylogeny of the Celastraceae inferred from 26S nuclear ribosomal DNA, phytochrome B, rbcl, atpB, and morphology. Molecular Phylogenetics and Evolution 19: 353-366.

Smith, A.C. 1940. The American Species of Hippocrateaceae. Brittonia 3: 341-555.

Smith, F.H. \& Smith, E.C. 1942. Anatomy of the inferior ovary of Darbia. American Journal of Botany 29: 464-471.

Smith, L.B. \& Robinson, H.E. 1971. Hippocrateáceas Pp. 1-33. In: R. Reitz (ed.). Flora Ilustrada Catarinense. Itajaí, Herbário Barbosa Rodrigues.

Solereder, H. 1908. Systematic Anatomy of the Dicotyledons: A Handbook for Laboratories of Pure and Applied Botany. Oxford, Clarendon Press.

Takhtajan, A. 1997. Diversity and Classification of Flowering Plants. New York, Columbia University Press. 